\title{
Childhood Obesity: Still a Major Concern
}

\author{
Subramani Parasuraman ${ }^{1, *}$, Venkateskumar Krishnamoorthy ${ }^{2}$
}

Subramani Parasuraman ${ }^{1, *}$, Venkateskumar Krishnamoorthy ${ }^{2}$

'Department of Pharmacology, Faculty of Pharmacy, AIMST University, Semeling, MALAYSIA. ${ }^{2}$ Department of Pharmaceutical Technology, Faculty of Pharmacy, AIMST University, Semeling, MALAYSIA.

Correspondence

Dr. Subramani Parasuraman

Department of Pharmacology, Faculty of Pharmacy, AIMST University, Semeling, MALAYSIA.

E-mail: parasuphd@gmail.com

DOI : 10.5530/fra.2021.2.6

Article Available online

http://www.antiox.org

\section{Copyright}

(c) 2021 Phcog.Net. This is an openaccess article distributed under the terms of the Creative Commons Attribution 4.0 International license.

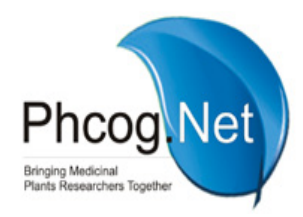

Overweight and obesity are defined as "abnormal or excessive fat accumulation that presents a risk to health". ${ }^{\prime}$ The prevalence of obesity is increasing every year and has nearly tripled since 1975 . More than 19 billon adults in 2016 and about 89 million children under the age 5 years are obese in $2020 .^{2}$ World Obesity Federation estimates suggest that about 250 million children ageing between 5 and 19 years old will be obese by 2030 . Reports also predict that the population of obese children (5 and 19 years) are expected to rise to 62 million in China, 27 million in India, 17 million in the USA, 1.8 million in Malaysia, 1.3 million in the UK and 0.08 million in Singapore by $2030 .{ }^{3}$ The complete data on 'Childhood Obesity' is available in 'Atlas of Childhood Obesity [2019 edition]' published by the World Obesity Federation, London. Again, the COVID-19 pandemic had significantly affected children's daily lives, reduced their physical activity, increased their stress levels and had contributed to such a high incidence of childhood obesity., 4 Woolford et al., assessed the changes in body-mass index (increased) among children during COVID19 restrictions and reported an increase in pediatric obesity during the aforesaid period. ${ }^{6}$

Childhood obesity is a complex health issue. Energy imbalance between calories consumed and calories expended is the fundamental cause of overweight and obesity. The causes of childhood obesity include genetics, changes in basal metabolic rate, parental perception and oxidative stress. Unhealthy eating habits, fast food consumption, higher intake of snacks, sugar-sweetened beverages, fast food consumption, eating while watching television, skipping breakfast and reduced numbers of family mealtimes during childhood are associated with increased rates of childhood obesity. ${ }^{8}$ Lack of physical activity and sedentary behaviour could be considered as the triggering factors for childhood obesity. 910

Pre-COVID-19 studies reported that children have a tendency to become obese in summer vacations due to a lack of physical activity. ${ }^{11}$ The same trend was observed in the COVID-19 pandemic period where children are exposed to lockdown, movement restrictions and implementation of online education. These factors contributed to further reduction in physical activity, psychomotor skills and verbal and nonverbal communication skills. Brown et al., highlighted the changes that occurred in health, learning aspects of children, and the parents also experienced changes in mood and general stress levels due to COVID-19 lockdown restrictions. ${ }^{12}$ Various environmental stressors during the COVID-19 period lead to an increase in oxidative stress levels and these risk factors contributed to the development of depressive symptoms. ${ }^{13}$ The lockdown period had led to a significant change in behavioural attitude, inadequate physical activity, consumption of high-calorie food and beverages contributed to the weight gain in children. ${ }^{11}$

Obesity in childhood could lead to noncommunicable diseases such as cardiovascular disease, musculoskeletal disorders, breathing problems, cancers, fatty liver disease, gallstones, and gastro-oesophagal reflux. Childhood obesity could lead to psychological problems such as anxiety and depression; social problems such as bullying and stigma; result in low self-esteem and lower the selfreported quality of life. ${ }^{14}$

Childhood obesity is preventable with coordinated efforts from the parents, teachers, family members, government organizations by providing appropriate awareness, social education and implementing sustainable proactive measures to provide a better future for the next generation.

\section{CONFLICT OF INTEREST}

The authors declare that there is no conflict of interest.

\section{REFERENCES}

1. Obesity. Available in https://www.who.int/health-topics/ obesity\#tab=tab_1. Last assessed on 27/11/20221.

2. Obesity and overweigh. Available in https://www. who.int/news-room/fact-sheets/detail/obesity-andoverweight. Last Assessed on. 27/11/2021.

3. The childhood obesity atlas. Available in https:// www.worldobesity.org/membersarea/global-atlas-onchildhood-obesity [Last assessed on 27/11/2021.

4. The Lancet Public Health. Childhood obesity beyond COVID-19. Lancet Public Health. 2021;6(8):e534. doi: 10.1016/S2468-2667(21)00168-7, PMID 34332666.

5. Moore SA, Faulkner G, Rhodes RE, Brussoni M, ChulakBozzer T, Ferguson LJ, et al. Impact of the COVID-19 virus outbreak on movement and play behaviours of Canadian children and youth: A national survey. Int $J$ Behav Nutr Phys Act. 2020;17(1):85. doi: 10.1186/ s12966-020-00987-8, PMID 32631350.

6. Woolford SJ, Sidell M, Li X, Else V, Young DR, Resnicow $\mathrm{K}$, et al. Changes in body mass index among children and adolescents during the COVID-19 pandemic. 
JAMA. 2021;326(14):1434-6. doi: 10.1001/jama.2021.15036, PMID 34448817.

7. Obesity and overweigh. Available in https://www.who.int/news-room/factsheets/detail/obesity-and-overweight. Last Assessed on. 27/11/2021.

8. Kim J, Lim H. Nutritional management in childhood obesity. J Obes Metab Syndr. 2019;28(4):225-35. doi: 10.7570/jomes.2019.28.4.225, PMID 31909365.

9. Sahoo K, Sahoo B, Choudhury AK, Sofi NY, Kumar R, Bhadoria AS. Childhood obesity: Causes and consequences. J Family Med Prim Care. 2015;4(2):187-92. doi: 10.4103/2249-4863.154628, PMID 25949965.

10. Kilic E, Özer ÖF, Erek Toprak A, Erman H, Torun E, Kesgin Ayhan S, et al. Oxidative stress status in childhood obesity: A potential risk predictor. Med Sci Monit. 2016 Oct 13;22:3673-9. doi: 10.12659/msm.897965, PMID 27733746.
11. Cuschieri S, Grech S. COVID-19: A one-way ticket to a global childhood obesity crisis? J Diabetes Metab Disord. 2020;19(2):1-4. doi: 10.1007/s40200-02000682-2, PMID 33173756.

12. Brown SM, Doom JR, Lechuga-Peña S, Watamura SE, Koppels T. Stress and parenting during the global COVID-19 pandemic. Child Abuse Negl. 2020;110(2):104699. doi: 10.1016/j.chiabu.2020.104699.

13. Bakadia BM, Boni BOO, Ahmed AAQ, Yang G. The impact of oxidative stress damage induced by the environmental stressors on COVID-19. Life Sci. 2021;264:118653. doi: 10.1016/j.Ifs.2020.118653.

14. Childhood obesity causes and consequences. Available in https://www.cdc. gov/obesity/childhood/causes.html [Last assessed on 27/12/2021].

Cite this article: Parasuraman S, Krishnamoorthy V. Childhood Obesity: Still a Major Concern. Free Radicals and Antioxidants. 2021;11(2):27-8. 